OPEN ACCESS

Edited by:

Coen Ottenheijm

VU University Medical Center,

Netherlands

Reviewed by:

Lori A. Walker,

University of Colorado Denver, USA

Diederik Wouter Dimitri Kuster,

VU University Medical Center,

Netherlands

${ }^{*}$ Correspondence:

José R. Pinto

jose.pinto@med.fsu.edu

Specialty section

This article was submitted to

Striated Muscle Physiology,

a section of the journal

Frontiers in Physiology

Received: 20 January 2017

Accepted: 27 March 2017

Published: 20 April 2017

Citation:

Veltri T, Landim-Vieira M, Parvatiyar MS, Gonzalez-Martinez D, Dieseldorff Jones KM, Michell CA,

Dweck D, Landstrom AP, Chase PB and Pinto JR (2017) Hypertrophic

Cardiomyopathy Cardiac Troponin C Mutations Differentially Affect Slow

Skeletal and Cardiac Muscle

Regulation. Front. Physiol. 8:221 doi: 10.3389/fphys.2017.00221

\section{Hypertrophic Cardiomyopathy Cardiac Troponin C Mutations Differentially Affect Slow Skeletal and Cardiac Muscle Regulation}

Tiago Veltri ${ }^{1}$, Maicon Landim-Vieira ${ }^{1}$, Michelle S. Parvatiyar ${ }^{2}$, David Gonzalez-Martinez ${ }^{1}$, Karissa M. Dieseldorff Jones ${ }^{1}$, Clara A. Michell ${ }^{1}$, David Dweck ${ }^{1}$, Andrew P. Landstrom ${ }^{3}$, P. Bryant Chase ${ }^{4}$ and Jose R. Pinto ${ }^{1 *}$

${ }^{1}$ Department of Biomedical Sciences, Florida State University College of Medicine, Tallahassee, FL, USA, ${ }^{2}$ Department of Molecular and Cellular Pharmacology, University of Miami Miller School of Medicine, Miami, FL, USA, ${ }^{3}$ Section of Pediatric Cardiology, Department of Pediatrics, Baylor College of Medicine, Houston, TX, USA, ${ }^{4}$ Department of Biological Science, Florida State University, Tallahassee, FL, USA

Mutations in TNNC1 - the gene encoding cardiac troponin C (cTnC) - that have been associated with hypertrophic cardiomyopathy $(\mathrm{HCM})$ and cardiac dysfunction may also

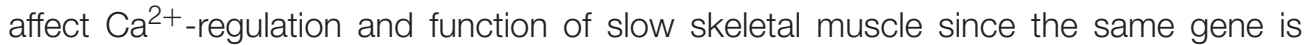
expressed in both cardiac and slow skeletal muscle. Therefore, we reconstituted rabbit soleus fibers and bovine masseter myofibrils with mutant cTnCs (A8V, C84Y, E134D, and D145E) associated with HCM to investigate their effects on contractile force and ATPase rates, respectively. Previously, we showed that these HCM cTnC mutants, except for $\mathrm{E} 134 \mathrm{D}$, increased the $\mathrm{Ca}^{2+}$ sensitivity of force development in cardiac preparations. In the current study, an increase in $\mathrm{Ca}^{2+}$ sensitivity of isometric force was only observed for the C84Y mutant when reconstituted in soleus fibers. Incorporation of cTnC C84Y in bovine masseter myofibrils reduced the ATPase activity at saturating $\left[\mathrm{Ca}^{2+}\right]$, whereas, incorporation of CTnC D145E increased the ATPase activity at inhibiting and saturating $\left[\mathrm{Ca}^{2+}\right]$. We also tested whether reconstitution of cardiac fibers with troponin complexes containing the cTnC mutants and slow skeletal troponin I (ssTnl) could emulate the slow skeletal functional phenotype. Reconstitution of cardiac fibers with troponin complexes containing ssTnl attenuated the $\mathrm{Ca}^{2+}$ sensitization of isometric force when $\mathrm{cTnC}$ A8V and D145E were present; however, it was enhanced for C84Y. In summary, although the A8V and D145E mutants are present in both muscle types, their functional phenotype is more prominent in cardiac muscle than in slow skeletal muscle, which has implications for the protein-protein interactions within the troponin complex. The C84Y mutant warrants further investigation since it drastically alters the properties of both muscle types and may account for the earlier clinical onset in the proband.

Keywords: cardiac troponin C, hypertrophic cardiomyopathy, slow skeletal muscle, skinned fibers, myofibrillar ATPase 


\section{INTRODUCTION}

Hypertrophic cardiomyopathy (HCM) is a cardiac disease with relatively high prevalence (1:200) in the general population, which promotes morphological changes of the heart such as left ventricular thickening (Semsarian et al., 2015). The first case of HCM was described in a patient from the 1950's (Teare, 1958) in which the diagnosis of HCM development was solely based on electrocardiogram analyses associated with angiographic/hemodynamic studies. After 1990, the development of DNA-based sequencing methodologies provided a valuable resource which accelerated a new era of HCM diagnosis with the discovery of the first mutation in the ß-myosin heavy chain gene, MYH7 (Geisterfer-Lowrance et al., 1990). Currently, it is widely accepted that mutations in sarcomeric genes lead to intracellular alterations that manifest as cardiac remodeling and pathologic hypertrophy (Force et al., 2010; Marian, 2010; Harvey and Leinwand, 2011; Seidman and Seidman, 2011; Maron and Maron, 2013).

After two decades of extensive genetic investigation and over 1,400 mutations identified, many genes encoding thin and thick filament, and cytoskeletal proteins have been established as the etiological agents of HCM (Maron et al., 2012). The most common mutations are located in thick-filament encoding genes (MYH7 and MBPC3), representing 50-70\% of all HCM patients that exhibit positive genetic test results. Meanwhile, mutations in genes that encode thin-filament proteins, such as the troponin ( $\mathrm{Tn}$ ) complex, have also been shown to occur with relatively high incidence compared to other canonical sarcomeric HCM genes (Willott et al., 2010; Brouwer et al., 2011; Maron et al., 2012). HCM-associated mutations lead to several alterations in cardiac contraction e.g., changes in myosin ATPase activity, actomyosin crossbridge interaction, cooperativity of muscle activation, $\mathrm{Ca}^{2+}$ binding to the thin filament, and a host of other HCM predisposing factors (Willott et al., 2010). In general, mutations in the regulatory proteins (tropomyosin and Tn) that are linked to HCM are associated with an increase in myofilament $\mathrm{Ca}^{2+}$ sensitivity; thus promoting changes in $\mathrm{Ca}^{2+}$ homeostasis and triggering development of cardiac dysfunction and arrhythmias seen in HCM patients (Willott et al., 2010; Brouwer et al., 2011; Landstrom and Ackerman, 2012).

Limited studies of HCM patients' skeletal muscle have identified abnormalities in electromyographic (EMG) and/or histologic analyses (Hootsmans and Meerschwam, 1971; Smith et al., 1976; Lochner et al., 1981; Przybojewski et al., 1981). In 1989, Caforio et al. (1989) showed that skeletal muscle dysfunction occurred in 37\% of HCM patients analyzed and found that this dysfunction arose from myogenic origins. This finding was independently verified in skeletal muscle biopsies. The authors also observed selective atrophy of type I muscle fibers in these patients (Caforio et al., 1989). Moreover, a recent clinical study which examined $46 \mathrm{HCM}$ patients by EMG showed evidence of subclinical skeletal muscle myopathy in 13 of the patients (28\%) (Karandreas et al., 2000).

Many genes for cardiac sarcomeric proteins are also expressed in some skeletal muscles; these include B-myosin heavy chain (MYH7), regulatory myosin light chain-2 (MYL2), desmin (DES), and troponin C (TNNC1) (Li et al., 1989; Matsuoka et al., 1989; Macera et al., 1992; Song et al., 1996). Mutations in the MYH7 gene can produce simultaneous abnormalities in cardiac and slow-twitch skeletal muscle function that can culminate as cardiomyopathy and/or myopathy (Hedera et al., 2003; Tajsharghi et al., 2003, 2007; Meredith et al., 2004; Mastaglia et al., 2005; Lamont et al., 2006, 2014; Darin et al., 2007; Overeem et al., 2007; Homayoun et al., 2011). Similarly, the MYL2 gene is expressed in both skeletal and cardiac muscle; mutations in myosin light chain appear to affect the function and morphology of both tissue types (Weterman et al., 2013). Desmin, a sarcomeric protein and a primary component of most intermediate filaments, is also a target of muscle disease. Desmin is expressed in cardiac, skeletal, and smooth muscle, and many studies have shown that mutations in the human DES gene promote adult-onset skeletal myopathy and, depending on which mutation, one of the three types of familial cardiomyopathies, i.e., dilated, hypertrophic, and restrictive (Goldfarb and Dalakas, 2009).

Troponin $\mathrm{C}(\mathrm{TnC})$ is a key regulatory protein in striated muscle contraction where its function is to bind $\mathrm{Ca}^{2+}$, which subsequently triggers actomyosin interactions and initiates muscle contraction (Farah and Reinach, 1995). The TNNC1 gene expresses $\mathrm{TnC}$ in both cardiac and slow skeletal muscle (Song et al., 1996). Seven mutations in TNNC1 (A8V, L29Q, A31S, C84Y, E134D, D145E, and Q122AfsX30) have been identified to date in HCM and restrictive cardiomyopathy patients (Hoffmann et al., 2001; Landstrom et al., 2008; Chung et al., 2011; Parvatiyar et al., 2012; Jaafar et al., 2015; Ploski et al., 2016). The A8V mutation was genetically knocked in and led to HCM in mice (Martins et al., 2015). Unfortunately, no clinical data regarding skeletal muscle abnormalities is available for these patients. With the exception of the E134D mutant, in vitro studies indicate that the above mentioned $\mathrm{cTnC}$ mutants alter contractile parameters known to underlie the development of diastolic dysfunction in these patients (Landstrom et al., 2008; Pinto et al., 2009, 2011a; Albury et al., 2012; Parvatiyar et al., 2012; Zot et al., 2016). Despite their extensive characterization in cardiac muscle, however, there are no reports on the effects of these HCM-associated TNNC1 mutations on slow skeletal muscle regulation and function.

The purpose of these in vitro studies was to identify potential pathogenic alterations in slow skeletal muscle regulation arising from the cTnC mutants. Therefore, we evaluated the effects of cTnC A8V, C84Y, E134D, and D145E mutants associated with $\mathrm{HCM}$ on the $\mathrm{Ca}^{2+}$ sensitivity and maximal force when reconstituted into skinned fibers from rabbit soleus, and maximal and minimal ATPase activities when reconstituted into bovine masseter muscle myofibrils. These muscle types were chosen for this study because they are type I fibers that only express myosin heavy chain I (MHC I) and show sufficient resilience after isolation that is suitable for each type of assay presented. Human TnC was utilized to accentuate translational value of the study. The primary sequence of $\mathrm{cTnC}$ is the same among human, porcine and bovine homologs, and rabbit cTnC differs by only one amino acid. Other Tn subunits including slow skeletal troponin I (ssTnI) homologs are largely similar (close to 99\% homologous) among human, bovine, porcine, and rabbit. 
However, it should be noted that rabbit slow skeletal troponin $\mathrm{T}$ (ssTnT) isoforms are less homologous to human, porcine, and bovine homologs. Utilization of proteins from different but overall largely homologous species has been widely accepted, although small functional differences cannot be discounted. Overall, we found that these cTnC mutants induce mutationdependent effects in slow skeletal muscle that were distinct from their effects in cardiac muscle; at least part of that distinction was found to depend on the TnI isoform. Our results are consistent with findings from other major muscle proteins encoded by the same gene in both cardiac and skeletal muscles. The data presented in this manuscript will be discussed in the context of the patients' clinical presentation.

\section{MATERIALS AND METHODS}

\section{SDS-PAGE for Myosin Heavy Chain (MHC) Separation}

Skeletal muscle MHC composition was analyzed by glycerolcontaining SDS-PAGE. Eight percent acrylamide gels were prepared and run according to Talmadge and Roy (1993). Protein concentration was measured using the Pierce ${ }^{\mathrm{TM}}$ Coomassie Plus (Bradford) Assay Kit (Bradford, 1976). Myofibrils and skeletal myosin (0.5-1 $\mu \mathrm{g})$ were boiled in sample buffer (Laemmli, 1970) for $2 \mathrm{~min}$ and loaded into glycerol-containing gels. 2mercaptoethanol was added to the upper electrode buffer at a final concentration of $10 \mathrm{mM}$. Gels were run at constant voltage $(75 \mathrm{~V})$ in a Bio-Rad Mini-PROTEAN Tetra System for $27 \mathrm{~h}$ at $8^{\circ} \mathrm{C}$. After, gels were stained with silver nitrite.

\section{Protein Expression and Purification}

Human cTnC (WT and mutants), ssTnI, and cardiac troponin $\mathrm{T}$ (cTnT) were expressed in E. coli and purified as described previously (Landstrom et al., 2008; Pinto et al., 2008a).

\section{Formation of Binary Complex ssTnl.cTnC}

Five different binary complexes (ssTnI.cTnC-WT, ssTnI.cTnCA8V, ssTnI.cTnC-C84Y, ssTnI.cTnC-E134D, and ssTnI.cTnCD145E) were assembled essentially as described previously (Pinto et al., 2008a) for use in displacement assays. After expression and purification, the individual human troponin subunits of ssTnI or cTnC (WT or mutants) were first dialyzed against a buffer containing high urea $(3 \mathrm{M})$ and $\mathrm{KCl}(1 \mathrm{M})$, then against two changes of buffer with the same salt composition but without urea. After this step, the protein concentration was determined using the Pierce ${ }^{T M}$ Coomassie Plus (Bradford) Assay Kit. Then ssTnI and individual cTnC (WT, A8V, C84Y, E134D, or D145E) proteins were mixed in a molar ratio of $1.3: 1$ ssTnI:cTnC. The protein mixtures were dialyzed against buffers of decreasing $\mathrm{KCl}$ concentration until binary complexes were formed (ssTnIcTnC). Next, the proteins were dialyzed into relaxing solution $\left(\mathrm{pCa} 8.0=10^{-8} \mathrm{M}\right.$ free $\left[\mathrm{Ca}^{2+}\right], 1 \mathrm{mM}$ free $\left[\mathrm{Mg}^{2+}\right], 7 \mathrm{mM}$ EGTA, $2.5 \mathrm{mM} \mathrm{MgATP}^{2-}$, $20 \mathrm{mM}$ MOPS, pH 7.0, $20 \mathrm{mM}$ creatine phosphate, ionic strength was adjusted to $I=0.15 \mathrm{M}$ using potassium propionate at $21^{\circ} \mathrm{C}$ ). Protein aggregates were removed by centrifugation and the binary complexes were stored at $-80^{\circ} \mathrm{C}$ until use.

\section{Skinned Fibers}

Slow skeletal skinned fibers were isolated from rabbit soleus muscle. New Zealand White rabbits were sacrificed and muscles were isolated in accordance with NIH guidelines and animal care protocol approved by the Animal Care and Use Committees of University of Miami and Florida State University. Soleus muscles were tied to toothpicks and excised at the resting, in vivo length from the experimental animals. After this, the slow skeletal fibers were immersed in relaxing low $\mathrm{Ca}^{2+}$ solution containing EGTA and $1 \%$ V/V Protease Inhibitor Cocktail (Sigma-Aldrich, P8340) (for details, see Pinto et al., 2008b).

For skinned cardiac preparations, left ventricular papillary muscles were dissected from fresh porcine hearts that were obtained from a local abattoir. Small muscle bundles were dissected and incubated overnight in relaxing low $\mathrm{Ca}^{2+}$ solution containing $1 \%$ Triton $\mathrm{X}-100$ at $4^{\circ} \mathrm{C}$ to remove membranes.

Both slow skeletal and cardiac preparations were stored at $-20^{\circ} \mathrm{C}$ in relaxing solution (pCa 8.0) plus glycerol (52\% $\mathrm{V} / \mathrm{V})$. For mechanical measurements, isolated slow skeletal fibers or cardiac muscle preparations were attached to a force transducer on one end and a microtranslator on the other end to adjust the length of the muscle preparation, and immersed initially in relaxing solution ( $\mathrm{pCa} 8.0$ with 15 units $/ \mathrm{ml}$ creatine phosphokinase added). Muscle preparations were stretched at pCa 8.0 by $20 \%$ over slack length. Initial, maximal $\mathrm{Ca}^{2+}$-activated force of slow skeletal fibers and cardiac preparations was tested in saturating $\mathrm{Ca}^{2+}$ conditions $(\mathrm{pCa}$ $4.0=10^{-4} \mathrm{M}$ free $\left[\mathrm{Ca}^{2+}\right]$ ) where the solution composition was otherwise the same as described above for relaxing solution.

\section{Extraction of Endogenous TnC from Slow Skeletal Skinned Fibers and Reconstitution with WT or HCM Mutant CTnC}

After the determination of initial, maximal, active force $\left(\mathrm{P}_{0}\right)$, the endogenous $\mathrm{TnC}$ was depleted by exposing slow skeletal skinned fibers to a CDTA extraction solution for fibers (5 mM 1,2cyclohexylenedinitrilotetraacetic acid (CDTA), pH 8.4 adjusted with dried Tris powder) for $1.5-2 \mathrm{~h}$, as described previously for extraction of $\mathrm{TnC}$ from skinned cardiac preparations (Landstrom et al., 2008). After successive washings with relaxing solution to remove CDTA, the residual active force at $\mathrm{pCa} 4.0$ was measured to determine the efficacy of $\mathrm{TnC}$ extraction. The average residual force values after extraction were $22.4 \pm 1.6$, $25.3 \pm 0.8,25.1 \pm 0.8,23.7 \pm 1.8,26.0 \pm 0.6 \%$ of $\mathrm{P}_{0}$ for fibers that were to be reconstituted with WT, A8V, C84Y, E134D, or D145E, respectively. The residual force after extraction was not statistically different (ANOVA and $t$-test) among the five groups of fibers. For reconstitution with $c \operatorname{TnC}$, the soleus fibers were successively exposed to drops of solution containing $28 \mu \mathrm{M} c \mathrm{cTnC}$, either WT or one of the mutants, in pCa 8.0 solution. TnC extraction and reconstitution were carried out at room temperature. To test the efficacy of $\mathrm{TnC}$ reconstitution, maximal force was tested again at $\mathrm{pCa} 4.0$ for comparison with $\mathrm{P}_{0}$. 


\section{Displacement of Endogenous cTn Complex from Cardiac Preparations and Reconstitution with Binary Complex ssTnl.cTnC-WT or ssTnl.cTnC-HCM mutant}

After measuring $\mathrm{P}_{0}$, the skinned cardiac preparations were equilibrated for $10 \mathrm{~min}$ in pre-incubation buffer $(250 \mathrm{mM} \mathrm{KCl}$, $20 \mathrm{mM}$ MOPS, $5 \mathrm{mM} \mathrm{MgCl} 2,5 \mathrm{mM}$ EGTA, $1 \mathrm{mM}$ DTT, $\mathrm{pH}$ 6.2) (Pinto et al., 2008a) without cTnT. The fibers were then treated for $2.5 \mathrm{~h}$ with $\sim 0.8 \mathrm{mg} / \mathrm{ml} \mathrm{cTnT}$ in the same buffer. The cTnT-treated fibers were subsequently washed in pre-incubation buffer without added cTnT to remove unbound, endogenous $\mathrm{Tn}$ complex and excess exogenous cTnT. The amount of endogenous Tn complex displaced by the excess cTnT was measured as the percentage of $\mathrm{Ca}^{2+}$-unregulated force, $\% \mathrm{UF}=([$ tension at $\mathrm{pCa}$ $8.0 /$ tension at pCa 4.0$] * 100$ ) (Pinto et al., 2008a). Subsequently, the fibers were incubated in $\mathrm{pCa} 8.0$ buffer containing pre-formed binary complex ssTnI.cTnC WT or mutant) for $1 \mathrm{~h}$ until the $\mathrm{Ca}^{2+}$-regulated force was restored (i.e., the fibers relaxed) and had reached steady state. All procedures were carried out at room temperature.

\section{$\mathrm{Ca}^{2+}$ Dependence of Force Development and Cooperativity of Slow Skeletal Fibers Containing cTnC mutants or Cardiac Preparations Containing ssTnl.cTnC mutants}

Measurement of $\mathrm{Ca}^{2+}$ sensitivity and cooperativity of thin filament activation of steady-state, isometric force were performed using slow skeletal skinned fibers (reconstituted with WT or mutant $\mathrm{cTnC}$ ) or skinned cardiac preparations (reconstituted with ssTnI.cTnC binary complexes containing WT or HCM mutants). The reconstituted slow skeletal or cardiac preparations were incubated in sequentially increasing $\left[\mathrm{Ca}^{2+}\right]$ solutions, ranging from $\mathrm{pCa} 8.0$ to 4.0 (decreasing pCa). The standard buffer for $\mathrm{Ca}^{2+}$ sensitivity curves was $1 \mathrm{mM}$ free $\left[\mathrm{Mg}^{2+}\right], 7 \mathrm{mM}$ EGTA, $2.5 \mathrm{mM} \mathrm{MgATP}{ }^{2-}, 20 \mathrm{mM}$ MOPS (pH 7.0), $20 \mathrm{mM}$ creatine phosphate, and 15 units $/ \mathrm{ml}$ creatine phosphokinase, $\mathrm{I}=150 \mathrm{mM}$ and free $\left[\mathrm{Ca}^{2+}\right]$ range from $10^{-8}$ to $10^{-4} \mathrm{M}$ ( $\mathrm{pCa} 8$ to $\mathrm{pCa} 4$ ). A pCa calculator program by Dweck et al. (2005) was used to calculate free $\left[\mathrm{Ca}^{2+}\right]$ in the $\mathrm{pCa}$ solutions. Force measurements were conducted at room temperature $\left(\sim 21^{\circ} \mathrm{C}\right)$. Steady-state, isometric force data were normalized and fit to the 4-parameter Hill equation (Hill, 1910):

$$
P=\frac{P_{0}\left[\mathrm{Ca}^{2+}\right]^{n_{\text {Hill }}}}{\left[\mathrm{Ca}^{2+}\right]^{n_{\text {Hill }}}+\left[\mathrm{Ca}_{50}^{2+}\right]^{n_{\text {Hill }}}}+P_{\text {min }}
$$

where $P_{0}$ is the maximal force, $P$ is the normalized force, " $\left[\mathrm{Ca}_{50}^{2+}\right]$ " is the free $\left[\mathrm{Ca}^{2+}\right]$ that produces $50 \%$ force and the exponent " $n_{\text {Hill }}$ " is the Hill coefficient, which is related to the steepness of the relationship around $\left[\mathrm{Ca}_{50}^{2+}\right]$ and is an indicator of apparent cooperativity for $\mathrm{Ca}^{2+}$ activation of steady-state force. The $\left[\mathrm{Ca}_{50}^{2+}\right]$ parameter estimates obtained from regression are reported as $\mathrm{pCa}_{50}$ (i.e., $-\log \left[\mathrm{Ca}_{50}^{2+}\right]$.

\section{Myofibril Preparation}

Rabbit soleus and diaphragm myofibrils used in Figure 1 were prepared as described previously (Solaro et al., 1971) and stored in $50 \%$ glycerol at $-20^{\circ} \mathrm{C}$. Rabbit back muscles myosin used in Figure 1 was prepared as described (Margossian and Lowey, 1982 ) and stored in $50 \%$ glycerol at $-20^{\circ} \mathrm{C}$. Myofibrils were prepared from porcine cardiac (used in Figure 3) and bovine masseter (used in Figures 1, 3) muscle, obtained from a local abattoir, as described previously (Solaro et al., 1971) and stored in $50 \%$ glycerol at $-20^{\circ} \mathrm{C}$. For SDS-PAGE analyses of MHC composition, rabbit soleus, rabbit diaphragm, bovine masseter myofibrils, and rabbit back muscles myosin from glycerol stocks were washed with MF buffer ( $30 \mathrm{mM}$ Imidazole, $60 \mathrm{mM} \mathrm{KCl}$, $2 \mathrm{mM} \mathrm{MgCl}_{2}, \mathrm{pH} 7.0,1 \mathrm{~V}$ myofibril or myosin/14V MF buffer). For myofibrillar ATPase activity assays, glycerol was removed by re-suspending and centrifuging the myofibrils using myofibril wash buffer containing $10 \mathrm{mM}$ MOPS, $10 \mathrm{mM} \mathrm{KCl,} 2 \mathrm{mM}$ dithiothreitol (DTT), pH 7.0 (1V myofibril/5V wash buffer x 3).

\section{Myofibrillar TnC Extraction and Reconstitution}

Native TnC was depleted from myofibrils by incubating in CDTA extraction buffer for myofibrils ( 5 mM CDTA, 5 mM DTT, pH 8.4 adjusted with dried Tris powder) for $\sim 2.5 \mathrm{~h}$ at room temperature. Every $30 \mathrm{~min}$, the sample was centrifuged and the supernatant

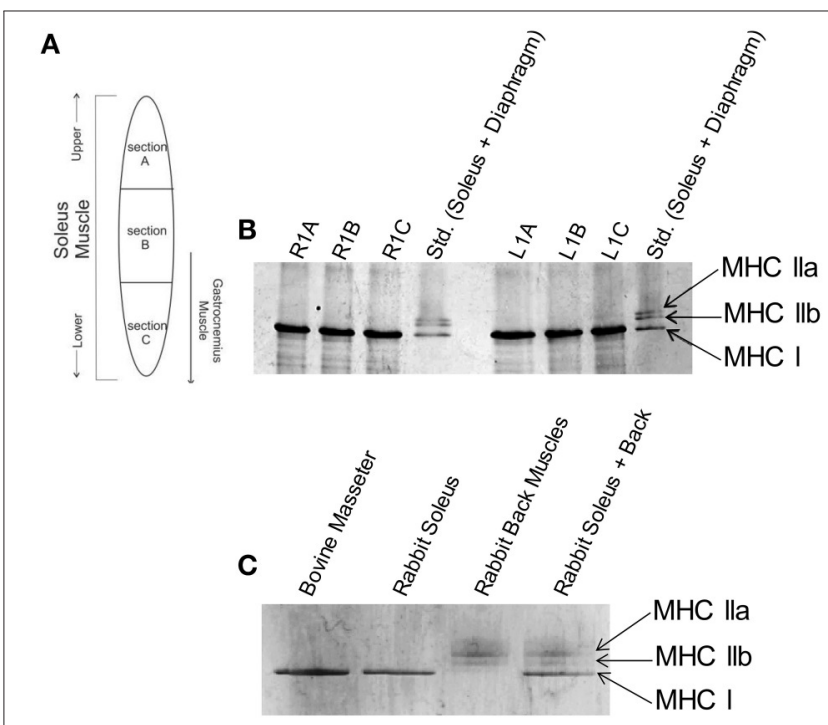

FIGURE 1 | Slow skeletal myosin heavy chain I is the predominant isoform throughout rabbit soleus and bovine masseter muscles. (A) Schematic of locations where muscle samples were collected from rabbit soleus muscle to determine whether there is a spatial gradient of different fiber types. (B) Glycerol SDS-PAGE shows that only the slow skeletal myosin isoform ( $\mathrm{MHC}$ I) is detectable throughout rabbit soleus muscle. Gel lanes are annotated as R1A-C or L1A-C to denote the right and left hind leg and sections A, B or C (labels in panel A) of the muscle. The standard (Std.) lanes contain rabbit soleus and diaphragm myofibrils, combined, to visualize all major skeletal muscle MHC isoforms. (C) Glycerol SDS-PAGE shows that $\mathrm{MHC} I$ is the only myosin isoform detectable in bovine masseter muscle myofibrils. Rabbit soleus myofibrils and rabbit back muscles myosin were used as standards for the visualization of other $\mathrm{MHC}$ isoforms. 
was discarded. At the end, myofibrils were washed three times in wash buffer to remove CDTA. Myofibrils were then reconstituted with cTnC-WT or-HCM mutants for $1 \mathrm{~h}$ at $4^{\circ} \mathrm{C}$. In order to minimize non-specific binding of $\mathrm{cTnC}$, the reconstituted samples were washed several times with myofibril wash buffer. Quantification of myofibril protein concentration was performed using the Pierce ${ }^{\mathrm{TM}}$ Coomassie Plus (Bradford) Assay Kit. Native, TnC-extracted, and TnC reconstituted myofibrils at $0.26 \mathrm{mg} / \mathrm{ml}$ were boiled in sample buffer (Laemmli, 1970) for $2 \mathrm{~min}$ and loaded into a $15 \%$ SDS-polyacrylamide gel.

\section{Myofibrillar ATPase Activity}

Myofibrillar ATPase assays were performed using a buffer containing $2 \mathrm{mM}$ EGTA, $3 \mathrm{mM}$ nitrilotriacetic acid (NTA), 20 $\mathrm{mM}$ MOPS, $1 \mathrm{mM}$ free $\mathrm{Mg}^{+2}, \sim 2.5 \mathrm{mM} \mathrm{MgATP}{ }^{2-}, \mathrm{pH}=7.0$ with a fixed $I=80 \mathrm{mM}$ and constant myofibril concentration of $0.4 \mathrm{mg} / \mathrm{ml}$ at $25^{\circ} \mathrm{C}$. Solutions were either pCa 8.0 or $\mathrm{pCa}$ 5.0. A pCa calculator program by Dweck et al. (2005) was used to calculate free $\left[\mathrm{Ca}^{2+}\right]$ in the pCa solutions. The reaction was initiated by adding $2.94 \mathrm{mM}$ ATP and quenched after 7 min by adding $4.6 \%$ trichloroacetic acid. After the assay reaction was terminated, precipitated proteins were removed by centrifugation for $7 \mathrm{~min}$, at 3,095 $\times \mathrm{g}$ and $4^{\circ} \mathrm{C}$. The concentration of inorganic phosphate in the supernatant, released by ATP hydrolysis, was measured using a colorimetric method according to the method of Fiske and Subbarow (1925).

\section{Statistical Analyses}

Data were tested for significant differences using Student's $t$ test (unpaired) and ANOVA with post-hoc Tukey's Honest Significant Difference (HSD) test. For Student's $t$-test, mutant protein data were always compared to WT within the same experimental condition. For ANOVA, a multiple comparison approach was used. Differences for all statistical tests were considered significant when $p<0.05$. When ANOVA yielded significance, Tukey's HSD test was then used to identify pairwise differences, and we report those differences found between mutant proteins vs. WT. Formally, multiple comparison using ANOVA is the statistically appropriate starting point, to be followed by a post-hoc test where significance was found by ANOVA. We have also included the results of pairwise comparisons using Student's $t$-tests where significance was found for consistency with prior work on cardiac muscle where only $t$-test analyses were performed. Our general interpretation is that ANOVA/Tukey's HSD is the more stringent test that identifies the strongest significant differences (which were also identified by $t$ tests), while those identified by $t$-test (alone) provide guidance for changes that may still prove to be relevant. The data were expressed as mean \pm S.E.M. Non-linear least squares regressions and Student's $t$-test analyses were performed using SigmaPlot software (version 12.0). ANOVA analyses and post-hoc Tukey's HSD tests were performed using $\mathrm{R}$ (version 3.3.2).

\section{RESULTS}

The effects of HCM-associated cTnC mutants on the regulation of cardiac myofilaments have been extensively characterized. In
Figure 1A, the schematic indicates the location of which muscle sections were excised from rabbit soleus muscle in order to assess whether different MHC isoforms are expressed within the sections. Figure 1B shows glycerol SDS-PAGE analysis of $\mathrm{MHC}$ isoforms in myofibrils isolated from rabbit soleus muscles, illustrating that only the slow-skeletal myosin isoform (i.e., MHC I) was uniformly detectable throughout these muscles. Glycerol SDS-PAGE analysis in Figure 1C shows, similarly, that only MHC I was detectable in bovine masseter muscle myofibrils.

We previously showed that cTnC A8V, C84Y, and D145E mutants increased $\mathrm{Ca}^{2+}$ sensitivity of steady-state, isometric force development when reconstituted into skinned cardiac preparations, while the cTnC E134D mutant did not affect $\mathrm{Ca}^{2+}$ sensitivity (Table 1) (Landstrom et al., 2008). Here, we determined the effects of the HCM cTnC mutants on the regulation of slow skeletal fibers. To accomplish this, TnC-depleted skinned fibers from rabbit soleus muscle were reconstituted with one of the exogenous cTnC proteins (WT, A8V, C84Y, E134D, or D145E). Only the C84Y mutant displayed a significant increase in the $\mathrm{Ca}^{2+}$ sensitivity of force development and a decrease of the $n_{\text {Hill }}$ ( $t$-test and ANOVA/Tukey HSD, Figure $2 \mathbf{A}$ and Table $\mathbf{1}$ ). The $\mathrm{pCa}_{50}$ (i.e., - $\log$ free $\left[\mathrm{Ca}^{2+}\right]$ which yields a half-maximal response, where $\left[\mathrm{Ca}^{2+}\right]$ is in molar units) obtained for cTnC C84Y reconstituted slow skeletal fibers was $6.33 \pm 0.07$; whereas, the $\mathrm{pCa}_{50}$ of fibers reconstituted with WT cTnC was $6.00 \pm 0.03$. Moreover, when comparing the $\mathrm{Ca}^{2+}$ sensitization associated with the cTnC C84Y mutant between reconstituted slow skeletal and cardiac fibers, the slow skeletal muscle fibers further accentuated this effect. This difference is reflected in the $\Delta \mathrm{pCa}_{50}$ (difference between the $\mathrm{pCa}_{50}$ of fibers reconstituted with cTnC $\mathrm{C} 84 \mathrm{Y}$ and $\mathrm{WT}$ ) of slow skeletal muscle $(+0.33 \log$ units $)$ and cardiac muscle $(+0.27 \log$ units; Landstrom et al., 2008) (Table 1). The $n_{\text {Hill }}$ for slow skeletal fibers containing cTnC C84Y was significantly lower than WT, $1.26 \pm 0.05$ vs. 1.61 \pm 0.07 (Figure 2A and Table 1).

Although reconstitution of the cTnC A8V or D145E mutants into skinned cardiac fibers led to an increase in the $\mathrm{Ca}^{2+}$ sensitivity of contraction (Landstrom et al., 2008), this was not observed in the slow skeletal fibers (compared to WT cTnC reconstituted soleus fibers; Figure $\mathbf{2 A}$ and Table 1), suggesting that the presence of slow skeletal proteins could play a crucial role in normalizing the $\mathrm{Ca}^{2+}$ sensitivity of contraction. The $n_{\text {Hill }}$ values of soleus muscle fibers reconstituted with cTnC A8V or D145E were not statistically different from the WT control, indicating that in slow skeletal muscle, these cTnC mutants do not alter cooperativity (Table $\mathbf{1}$ ).

Reconstitution of the cTnC E134D mutant did not alter the $\mathrm{Ca}^{2+}$ sensitivity or $n_{\mathrm{Hill}}$ of either skinned cardiac or slow skeletal preparations (Figure 2A and Table 1). Additionally, no significant differences in the maximal force were observed among slow skeletal fibers that were reconstituted with the WT or any of the four HCM cTnC mutants (Figure 2B and Table 1).

To assess the effects of the cTnC mutants on myofibrillar ATPase activity, we performed assays comparing the ATPase activity of both cardiac and slow skeletal myofibrils reconstituted with recombinant WT cTnC or mutants. Supplementary Figure 1 shows the SDS-PAGE analysis of cardiac and slow skeletal 

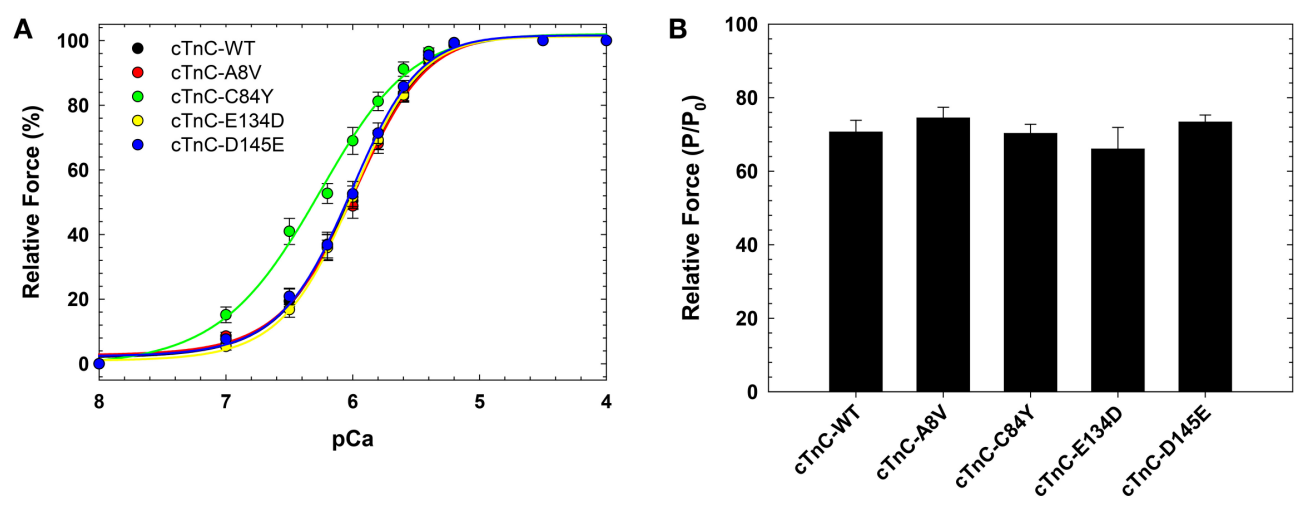

FIGURE 2 | $\mathrm{Ca}^{2+}$ dependence of steady-state, isometric force development in rabbit soleus fibers reconstituted with recombinant cTnC proteins. (A) $\mathrm{Ca}^{2+}$ sensitivity of contraction in skinned fibers reconstituted with WT and HCM cTnC mutants (A8V, C84Y, E134D, and D145E). (B) Maximal force (pCa 4) following reconstitution normalized to the initial tension $\left(\mathrm{P} / \mathrm{P}_{0}\right)$ in fibers reconstituted with WT or HCM cTnC mutants. Regression parameter estimates of pCa50 and $n_{\mathrm{Hill}}$, along with $\Delta \mathrm{pCa}_{50}$ and relative maximal force values for these experiments are summarized in Table 1. Data are shown as mean \pm S.E.M.

TABLE 1 | Parameter summary for $\mathrm{Ca}^{2+}$ dependence of steady-state isometric force in skinned porcine cardiac and rabbit soleus muscle preparations reconstituted with WT cTnC or CTnC HCM mutants.

\begin{tabular}{|c|c|c|c|c|c|c|}
\hline Muscle & TnC (WT and mutants) & $\mathrm{pCa}_{50}$ & $\Delta \mathrm{pCa}_{50}$ & $n_{\text {Hill }}$ & Maximal force (\%) & \# Experiments \\
\hline \multirow[t]{5}{*}{ Slow Skeletal } & WT & $6.00 \pm 0.03$ & & $1.61 \pm 0.07$ & $70.65 \pm 3.22$ & 10 \\
\hline & A8V & $6.01 \pm 0.04$ & +0.01 & $1.65 \pm 0.09$ & $74.47 \pm 2.96$ & 16 \\
\hline & C84Y & $6.33 \pm 0.07^{\star, \#}$ & +0.33 & $1.26 \pm 0.05^{\star, \#}$ & $70.26 \pm 2.51$ & 11 \\
\hline & E134D & $6.01 \pm 0.03$ & +0.01 & $1.68 \pm 0.09$ & $66.00 \pm 5.92$ & 8 \\
\hline & D145E & $6.05 \pm 0.04$ & +0.05 & $1.63 \pm 0.08$ & $73.35 \pm 1.94$ & 11 \\
\hline \multirow[t]{5}{*}{ Cardiac $^{\mathrm{a}}$} & WT & $5.66 \pm 0.01$ & & $2.74 \pm 0.19$ & $59.1 \pm 2.3$ & 8 \\
\hline & A8V & $6.02 \pm 0.01^{\star}$ & +0.36 & $2.68 \pm 0.18$ & $72.4 \pm 2.7^{\star}$ & 9 \\
\hline & C84Y & $5.93 \pm 0.01^{*}$ & +0.27 & $2.42 \pm 0.15^{\star}$ & $59.5 \pm 3.7$ & 8 \\
\hline & E134D & $5.68 \pm 0.01$ & +0.02 & $2.82 \pm 0.16$ & $58.4 \pm 2.1$ & 7 \\
\hline & D145E & $5.90 \pm 0.01^{\star}$ & +0.24 & $2.73 \pm 0.17$ & $70.3 \pm 1.4^{*}$ & 8 \\
\hline
\end{tabular}

a Values from Landstrom et al. (2008).

$\Delta p \mathrm{Ca}_{50}=\mathrm{pCa}_{50}$ of mutant TnC-pCa $\mathrm{a}_{50}$ of WT TnC.

${ }^{*} p<0.05$ HCM mutant vs. WT tested with Student's t-test.

$\# p<0.05$ from ANOVA and $p<0.05$ from post-hoc Tukey's HSD test for HCM mutant vs. WT.

myofibrils, demonstrating TnC extraction from native myofibrils followed by cTnC reconstitution. At inhibiting (sub-diastolic) $\mathrm{Ca}^{2+}$ concentration ( $\mathrm{pCa} 8.0$ ), cardiac myofibrils reconstituted with cTnC D145E ( $t$-test and ANOVA/Tukey's HSD), or C84Y and D145E ( $t$-tests) displayed significantly higher activities than cardiac myofibrils reconstituted with the WT control (Figure 3A and Table 2). This suggests that the cTnC D145E mutant, and possibly also the C84Y mutant, modifies inhibitory processes within cardiac muscle at low levels of $\mathrm{Ca}^{2+}$. At maximal activating $\mathrm{Ca}^{2+}$ (pCa 5.0), cardiac myofibrils reconstituted with cTnC A8V, C84Y, or D145E exhibited higher levels of myofibrillar ATPase activity when individually compared to the WT control ( $t$-tests), although no significant differences were identified by ANOVA (Figure 3A and Table 2). Differences in muscle regulation by the cTnC mutants were especially evident for the C84Y and D145E mutants in slow skeletal myofibrils. In the slow skeletal muscle background, cTnC C84Y decreased the myofibrillar ATPase activity at maximally activating $\mathrm{Ca}^{2+}$ ( $\mathrm{pCa} 5.0$ ) when compared to the WT control ( $t$-test and ANOVA/Tukey HSD; Figure 3B and Table 2). The effect of reconstituting the D145E mutant in slow skeletal myofibrils showed similar trends in ATPase activity to those observed in cardiac myofibrils: the D145E mutant increased ATPase activity at both low and high $\mathrm{Ca}^{2+}$ concentrations when compared to the WT control ( $t$-test and ANOVA/Tukey HSD; Figure 3B and Table 2).

Although cTnC A8V and D145E are capable of altering the physiological properties of cardiac muscle contraction (e.g., $\Delta \mathrm{pCa}_{50}$ of +0.36 and +0.24 , respectively), these mutants did not substantially alter the corresponding properties of slow skeletal muscle (Table 1). The presence of slow skeletal thin filament proteins may have counteracted the enhancement of apparent $\mathrm{Ca}^{2+}$ affinity at cTnC's $\mathrm{N}$-terminal regulatory $\mathrm{Ca}^{2+}$ binding site which was observed in the cardiac preparations reconstituted 

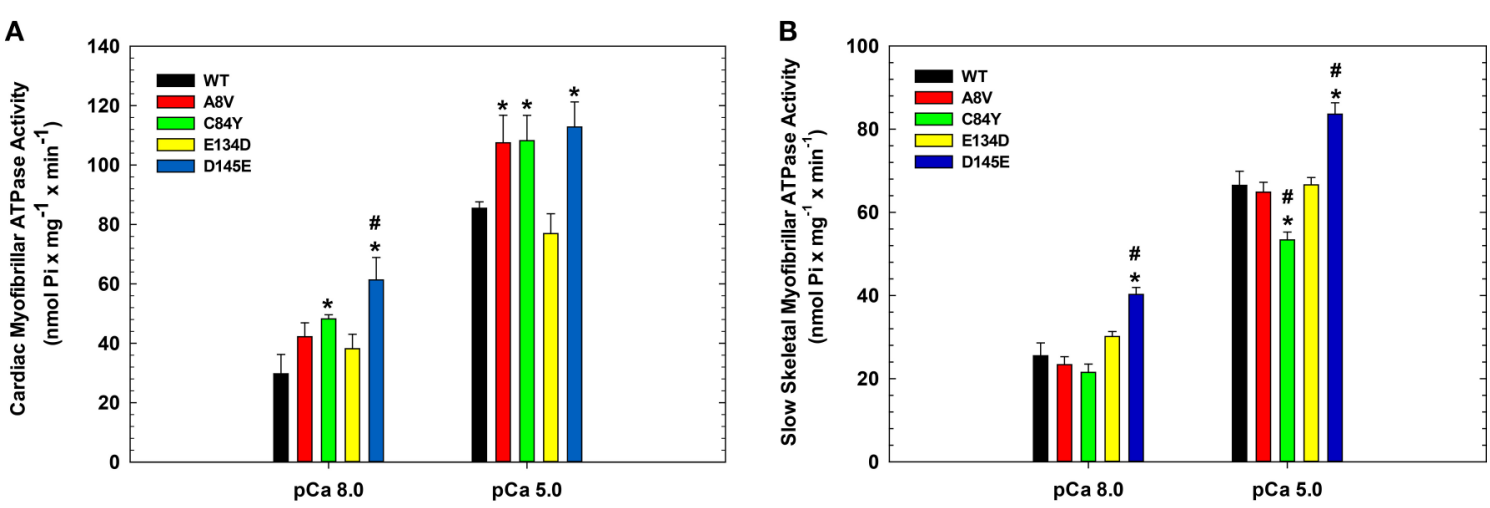

FIGURE 3 | Myofibrillar ATPase activity of (A) porcine cardiac and (B) bovine masseter muscle myofibrils that were depleted of ThC and reconstituted with WT cTnC or cTnC HCM mutants. ( $\left.{ }^{*}\right)$ Indicates significant differences ( $p<0.05$, Student's $t$-test) for mutant cTnCs compared to WT in the same muscle type and pCa. (\#) Indicates significant differences ( $p<0.05$, ANOVA/Tukey's HSD) for mutant cTnCs compared to WT in the same muscle type and pCa. ATPase values for these experiments are summarized in Table 2. Data are shown as mean \pm S.E.M.

TABLE 2 | Summary of $\mathrm{Ca}^{2+}$ dependent ATPase activities from porcine cardiac and bovine masseter myofibrils reconstituted with WT cTnC or cTnC HCM mutants.

\begin{tabular}{|c|c|c|c|c|c|}
\hline & WT & A8V & C84Y & E134D & D145E \\
\hline \multicolumn{6}{|l|}{ CARDIAC MYOFIBRILS } \\
\hline Min. ATPase activity (pCa 8.0) & $29.70 \pm 6.52$ & $42.19 \pm 4.67$ & $48.20 \pm 1.39^{*}$ & $38.14 \pm 4.87$ & $61.33 \pm 7.58^{\star}, \#$ \\
\hline Max. ATPase activity (pCa 5.0) & $85.44 \pm 2.17$ & $107.50 \pm 9.29^{\star}$ & $108.20 \pm 8.55^{\star}$ & $76.94 \pm 6.67$ & $112.83 \pm 8.41^{\star}$ \\
\hline \multicolumn{6}{|l|}{ SLOW SKELETAL MYOFIBRILS } \\
\hline Min. ATPase activity (pCa 8.0) & $25.50 \pm 3.10$ & $23.35 \pm 1.91$ & $21.50 \pm 2.01$ & $30.13 \pm 1.22$ & $40.25 \pm 1.67^{\star, \#}$ \\
\hline Max. ATPase activity (pCa 5.0) & $66.50 \pm 3.41$ & $64.84 \pm 2.37$ & $53.38 \pm 1.89^{*} \#$ & $66.63 \pm 1.76$ & $83.63 \pm 2.72^{\star, \#}$ \\
\hline
\end{tabular}

Values are shown as nmol Pix $\mathrm{mg}^{-1} \times \mathrm{min}^{-1}$.

Min = minimum and Max = maximum

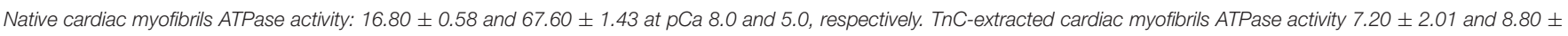
2.43 at $p$ Ca 8.0 and 5.0, respectively.

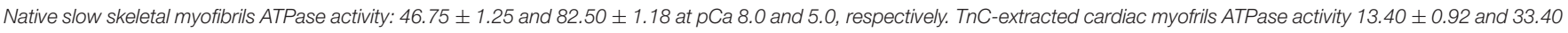
\pm 2.31 at $p \mathrm{Ca} 8.0$ and 5.0, respectively.

${ }^{*} p<0.05$ HCM mutant vs. WT tested with Student's t-test.

$\# p<0.05$ from ANOVA and $p<0.05$ from post-hoc Tukey's HSD test for HCM mutant vs. WT.

Cardiac myofibrils, $n=5-7$.

Slow skeletal myofibrils, $n=8-14$.

with cTnC A8V or D145E. To better understand the influence of the different sarcomeric isoforms (i.e., cardiac vs. slow skeletal) on these phenomena, we tested whether these effects are partially or totally attributed to the presence of ssTnI. Therefore, we exchanged the endogenous cTn complex of skinned cardiac fibers with exogenous chimeric Tn complexes comprised of cTnC, ssTnI, and cTnT. To assess the amount of displaced endogenous cTn achieved by the cTnT displacement method, we recorded the average values of the cardiac preparation's $\mathrm{Ca}^{2+}$-unregulated force (i.e., force generated by preparations that have displaced cTnC and cTnI by incubation with cTnT), which were: $88.5 \pm$ $3.4,82.1 \pm 4.2,80.2 \pm 7.2,86.7 \pm 8.4$, and $91.7 \pm 3.8 \%$ for preparations that were to be reconstituted with cTnC WT, A8V, C84Y, E134D, or D145E, respectively. After cTn displacement, cardiac preparations were incubated with the exogenous binary complex containing ssTnI and WT or mutant cTnC. Finally, the recovered maximal $\mathrm{Ca}^{2+}$ regulated force was recorded. The maximal force values were: $81.1 \pm 4.7,82.7 \pm 4.6,91.8 \pm 2.4$, $92.1 \pm 5.0$, and $84.4 \pm 4.1 \%$ of the $\mathrm{P}_{0}$ for WT, A8V, C84Y, E134D, and D145E, respectively. No significant differences in the $\mathrm{Ca}^{2+}$ unregulated force, as well as, the $\mathrm{Ca}^{2+}$-regulated maximal force among the five experimental groups existed ( $t$-test and ANOVA; Table 3).

Figure 4 indicates that incorporation of ssTnI into cardiac preparations partially attenuated the effects of cTnC A8V and $\mathrm{D} 145 \mathrm{E}$ on the $\mathrm{Ca}^{2+}$ sensitivity of force development. The $\triangle \mathrm{pCa}_{50}$ values for cardiac preparations reconstituted with cTnC A8V and D145E together with ssTnI were +0.09 and +0.18 , respectively (Figure 4 and Table 3); whereas, in skinned cardiac preparations reconstituted with $\mathrm{cTnC} \mathrm{A} 8 \mathrm{~V}$ and $\mathrm{D} 145 \mathrm{E}$ alone (i.e., in the presence of endogenous $\mathrm{cTnI}$ ), the $\Delta \mathrm{pCa}_{50}$ values were +0.36 and +0.24 , respectively (Table 1 ) (Landstrom et al., 2008). In contrast, in skinned cardiac preparations reconstituted with binary complex containing ss TnI and cTnC C84Y, the presence of 

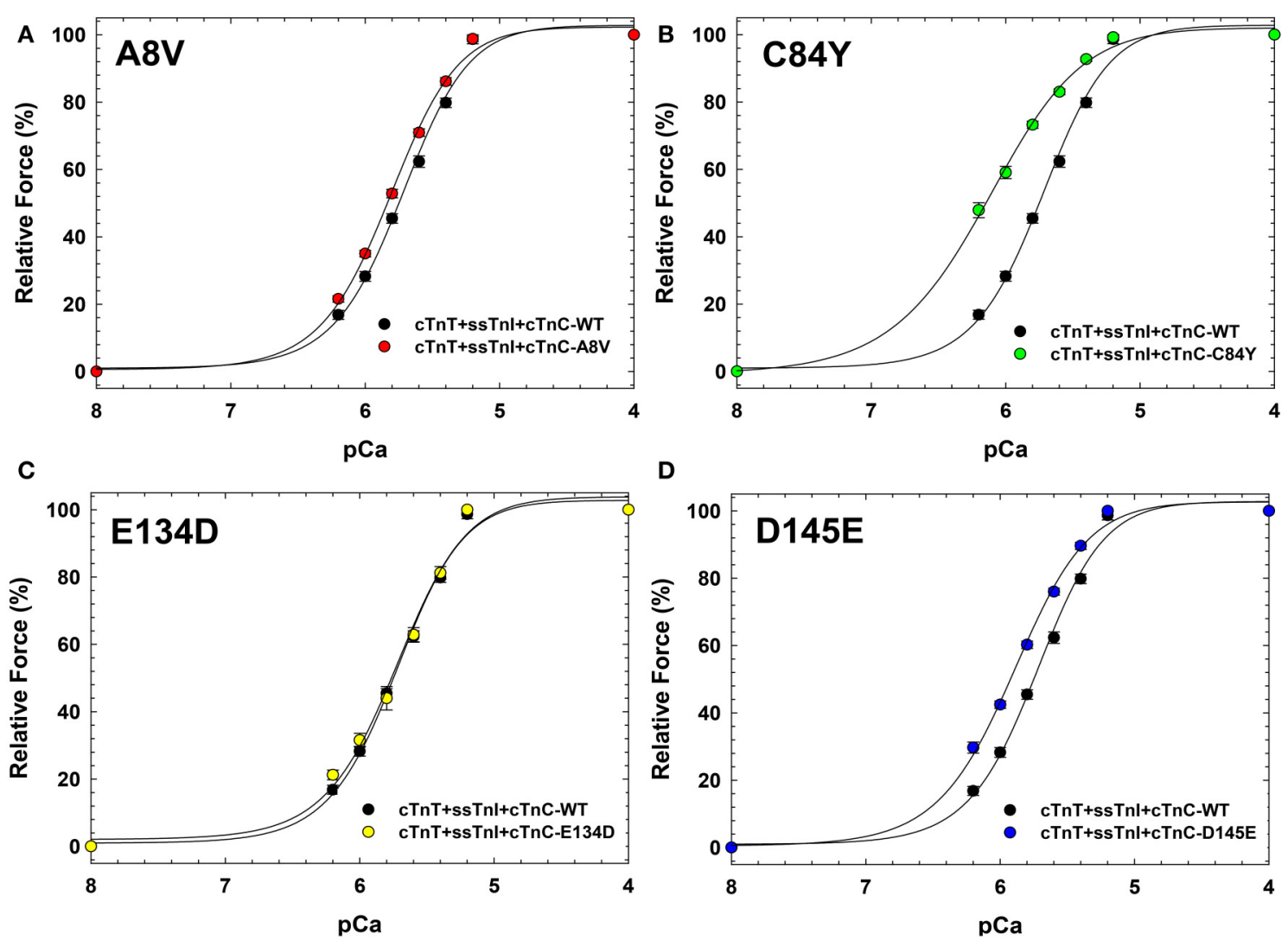

FIGURE $4 \mid \mathrm{Ca}^{2+}$ dependence of steady-state isometric force development in porcine cardiac preparations reconstituted with slow skeletal Tnl together with WT cTnC or CTnC HCM mutants. Comparisons of $\mathrm{Ca}^{2+}$ sensitivity of force development obtained for CTnC WT and HCM mutants, in (A) WT vs. A8V, (B) WT vs. C84Y, (C) WT vs. E134D, and (D) WT vs. D145E. Regression parameter estimates of pCa $\mathrm{F}_{50}$ and $n_{\text {Hill, }}$ along with $\Delta \mathrm{pCa} 50$ and relative maximal force values for these experiments are summarized in Table 3. Data are shown as mean \pm S.E.M.

TABLE 3 | Parameter summary for $\mathrm{Ca}^{2+}$ dependence of steady-state isometric force in skinned porcine cardiac preparations reconstituted with ssTnl together with WT CTnC or CTnC HCM mutants.

\begin{tabular}{lcccccc}
\hline ssTnl.cTnC (WT and mutants) & $\mathbf{p C a}_{\mathbf{5 0}}$ & $\mathbf{\Delta} \mathbf{p C a}_{\mathbf{5 0}}$ & $\boldsymbol{n}_{\text {Hill }}$ & Maximal force (P/Po)\% & \% Ca $^{2+}$ unregulated force & \# Experiments \\
\hline WT & $5.73 \pm 0.02$ & - & $1.74 \pm 0.04$ & $81.09 \pm 4.69$ & $88.51 \pm 3.38$ \\
A8V & $5.82 \pm 0.01^{*, \#}$ & +0.09 & $1.70 \pm 0.02$ & $82.68 \pm 4.64$ & $82.09 \pm 4.16$ \\
C84Y & $6.14 \pm 0.03^{*, \#}$ & +0.41 & $1.28 \pm 0.04^{*, \#}$ & $91.83 \pm 2.41$ & $80.20 \pm 7.15$ \\
E134D & $5.73 \pm 0.03$ & - & $1.71 \pm 0.11$ & $92.10 \pm 5.02$ & $86.67 \pm 8.43$ \\
D145E & $5.91 \pm 0.01^{*, \#}$ & +0.18 & $1.57 \pm 0.03^{*}$ & $84.42 \pm 4.11$ & $91.67 \pm 3.80$
\end{tabular}

The $\mathrm{Ca}^{2+}$ unregulated force following TnT incubation (to displace endogenous troponin) was calculated according to: $\left(P_{p C a 8} / P_{p C a 4}\right) \times 100$, where $P_{p C a 8}$ and $P_{p C a 4}$ are the forces generated at pCa 8.0 and pCa 4.0, respectively.

$\Delta p C a_{50}=p C a_{50}$ of mutant TnC-pCa50 of WT TnC.

${ }^{*} p<0.05$ HCM mutant vs. WT tested with Student's t-test.

$\# p<0.05$ from ANOVA and $p<0.05$ from post-hoc Tukey's HSD test for HCM mutant vs. WT.

ssTnI did not attenuate the myofilament $\mathrm{Ca}^{2+}$ sensitization that was observed in the presence of endogenous cTnI. These cardiac preparations exhibited an even higher $\mathrm{Ca}^{2+}$ sensitivity of force development than what was observed in cardiac preparations containing the cardiac isoform of $\operatorname{TnI}\left(\Delta \mathrm{pCa}_{50}+0.41\right.$ or +0.27 , respectively; Tables 1, 3). A comparison of $n_{\text {Hill }}$ regression parameter estimates obtained from skinned cardiac preparations reconstituted with ssTnI and HCM cTnC mutants indicates that the C84Y ( $t$-test and ANOVA/Tukey's HSD) and D145E ( $t$-test) mutants significantly reduced apparent cooperativity in comparison to the WT control $(1.28 \pm 0.04,1.57 \pm 0.03$, and $1.74 \pm 0.04$ for C84Y, D145E, and WT, respectively; Table 3). The cardiac preparations reconstituted with exogenous ssTnI and cTnC E134D showed no significant changes in relation to 
the $\mathrm{pCa}_{50}$ and $n_{\text {Hill }}(t$-test and ANOVA/Tukey's HSD) when compared with WT control (Figure 4 and Table 3).

\section{DISCUSSION}

Patients that exhibit cardiomyopathy and possess a positive family history are routinely screened for mutations in a number of thin and thick filament encoding genes. Obvious clinical symptoms such as dyspnea, syncope, chest pain, and arrhythmia-in addition to characteristic cardiac remodeling revealed through imaging-are frequently documented complaints. Many sarcomeric mutations that are identified on the basis of cardiac dysfunction, however, are also expressed in skeletal muscle. With the clinical focus on the heart, more subtle skeletal muscle abnormalities may go undetected (Towbin, 2014). We are interested in whether these mutations may have pathogenic consequences in skeletal muscle that go unreported and/or undetected. Here, we queried whether mutations in TNNC1 that are linked to HCM and expressed in slow skeletal muscle can manifest as a dysfunction or affect the contractile properties of slow skeletal muscle.

While the cardiac effects of TNNC1 mutants were first examined in the context of HCM pathogenic properties and disease causation, they have not been assessed in slow skeletal muscle. This study is the first to examine the effects of mutations present in the TNNC1 gene on slow skeletal muscle regulation (Song et al., 1996). We found that for most of the HCM cTnC mutants examined in this study, their incorporation into slow skeletal muscle ablated the increased $\mathrm{Ca}^{2+}$ sensitivity of force development that is seen in cardiac preparations. Only cTnC C84Y maintained its $\mathrm{Ca}^{2+}$ sensitizing effects in the slow skeletal muscle fibers. Surprisingly, the effects of this mutation were amplified when incorporated into the slow skeletal myofilament. This suggests that this mutant exerts distinct effects on a common element that exist within both muscle types. Since skeletal muscle comprises a large percentage of a person's mass, and slow type I muscle fibers are found throughout human musculature, it is reasonable to expect that slow muscle dysfunction could impart a substantial burden on the affected individual.

Differences in the protein structure of slow skeletal and cardiac TnI and TnT underlie the functional properties of these muscle types, especially when coupled with the distinctive properties of each mutant $\mathrm{cTnC}$ in this study. The overall structures of cardiac and skeletal muscle troponins are similar, at least in troponin's core domain (Takeda et al., 2003; Vinogradova et al., 2005). However, three major differences between skeletal and cardiac troponin structures may contribute to the differential effects: (1) structure of the TnI inhibitory segment is ordered in the skeletal muscle isoform but flexible and disordered in the cardiac isoform (Takeda et al., 2003; Vinogradova et al., 2005); (2) the position and conformation of the TnT2 N-terminal helix (Takeda et al., 2003; Vinogradova et al., 2005); and (3) cTnI contains an N-terminal extensionnot present in the skeletal isoforms-which harbors two serine residues capable of undergoing phosphorylation by protein kinase A (Zhang et al., 1995). Based upon the above, the experiments involving ssTnI would not be influenced by phosphorylation of the cardiac-specific, $\mathrm{N}$-terminal extention of cTnI.

The myofibrillar ATPase assays further explored the mechanism underlying the $\mathrm{Ca}^{2+}$ sensitization induced by the C84Y mutant in both types of muscle fibers. At saturating $\mathrm{Ca}^{2+}$ (pCa 5.0), slow skeletal ATPase activity was significantly reduced, while cardiac ATPase activity trended higher. In cardiac muscle, the residue $\mathrm{C} 84$ contacts the cTnI switch region when the $\mathrm{N}$-terminus of $\mathrm{cTnC}$ is in the open conformation and the BC loop of $\mathrm{cTnC}$ when it is in the closed conformation. Therefore, the C84Y mutant may stabilize the open conformation when bound to cTnI (Li and Hwang, 2015) and affect the critically important positioning of the cTnC N-domain (Hwang et al., 2014). Upon binding of divalent cations, the global structure of cTnC becomes more compact (Jayasundar et al., 2014; Badr et al., 2016), which could likely be influenced by mutations in the cTnC linker region. These alterations in the cTnC $\mathrm{N}$-domain may increase the affinity between cTnC-C84Y and the cTnI switch region and ultimately impact initiation of cardiac contraction. The switch region of cTnI (148-158) is immediately flanked by the inhibitory (136-147) and regulatory (161-209) regions, which anchors to actin during diastole (Tripet et al., 1997) and, in doing so, is largely responsible for inhibition of contractility at diastolic $\mathrm{Ca}^{2+}$ levels (Meyer and Chase, 2016). Increased affinity between cTnC-C84Y and the cTnI switch region would therefore be expected to reduce interactions between the cTnI inhibitory and regulatory regions during diastole, permitting actomyosin ATPase activity at subthreshold $\mathrm{Ca}^{2+}$ concentrations, thereby promoting greater ATPase activation at higher $\mathrm{Ca}^{2+}$ concentrations.

Based upon the study by Westfall et al. (1997) on ssTnIoverexpressing cardiomyocytes, the reduction in $\mathrm{Ca}^{2+}$ activation threshold in slow skeletal fibers containing cTnC-C84Y (Figure 2 and Table 1), may arise from altered interactions within individual regulatory units of the thin filament (7 actin monomers, 1 tropomyosin, and $1 \mathrm{cTn}$ complex). Weaker interactions between ssTnI and cTnC-C84Y may lower the threshold for $\mathrm{Ca}^{2+}$-activated development of tension and reduce cooperativity in cardiac muscle reconstituted with ssTnI. In addition, it is also possible that mutations in troponin differentially modulate the ATPase activity of myosin (Schoffstall et al., 2011; Chalovich, 2012) on top of their effects on $\mathrm{Ca}^{2+}$ activation of the thin filament. While $\mathrm{Ca}^{2+}$-activation of the cardiac thin filament is more dependent on cross-bridges than skeletal muscle (Gillis et al., 2007), cycling crossbridges at submaximally activating $\mathrm{Ca}^{2+}$ concentrations could result in reduced cooperativity in the presence of $\mathrm{Ca}^{2+}$-sensitizing mutations (Westfall et al., 1997). The less flexible TnI switch region in skeletal muscle appears to differently affect $\mathrm{Ca}^{2+}$ regulation of myofibrillar ATPase activity in the presence of the C84Y mutation in cTnC. The differential effect of C84Y on myofibrillar ATPase activity between tissue types suggests that the $\mathrm{C} 84 \mathrm{Y}$ mutation in $\mathrm{cTnC}$ could increase $\mathrm{Ca}^{2+}$ sensitivity of contraction in both muscles by distinct mechanisms. In cardiac muscle, it may increase the overall number of cycling crossbridges; while in the slow skeletal muscle, it may decrease 
the overall number of cycling cross-bridges and enhance the population of strongly bound cross-bridges.

The other HCM cTnC mutants examined in this study are located in distinct structural regions of cTnC. A8V is present in the cTnC N-helix, which plays a key role in defining the orientation of the $\mathrm{cTnC} \mathrm{N}$-domain relative to the troponin complex. As described above, alterations in cTnC Ndomain orientation can alter the affinity between the $\mathrm{cTnC}$ $\mathrm{N}$-domain and the cTnI switch peptide; these changes are likely responsible for increasing the cardiac myofibrillar ATPase activity at saturated $\mathrm{Ca}^{2+}$ concentration in this (Figure 3 and Table 2) and prior studies (Zot et al., 2016). However, cTnC-A8V does not affect slow skeletal myofibrillar ATPase measurements or alter cooperativity in cardiac preparations reconstituted with cTnC.ssTnI.cTnT. Functionally, the D145E mutant is distinct; it is located in the C-domain of cTnC and has been shown to increase the $\mathrm{Ca}^{2+}$ affinity of site II of isolated cTnC, cTn complex and the thin filament (Pinto et al., 2009). The D145E mutant has also been shown to increase cTnC binding affinity to the cardiac thin filament (Marques et al., 2017). The affinity between the TnI switch region and cTnC may be increased regardless of which TnI isoform is present, as indicated by increased activity of myofibrillar ATPase in both the slow skeletal and cardiac myofibrillar ATPase at both low and high $\mathrm{Ca}^{2+}$ concentrations (Figure 3 and Table 2). The D145E mutant did not affect the $\mathrm{Ca}^{2+}$ sensitivity of skinned slow skeletal fibers (Figure 2 and Table 1). Therefore, it could be speculated that new interactions/altered affinity between the cTnC D145E C-domain and ssTnT could potentially normalize the sensitizing effects of the mutant, which could be confirmed by peptide binding studies. The E134D mutant did not affect myofibrillar ATPase activity (Figure 3 and Table 2) or $\mathrm{Ca}^{2+}$-sensitivity of force development or cooperativity of thin filament activation (Figure 2 and Table $\mathbf{1}$ ) in either skeletal or cardiac preparations, further confirming the likelihood that it is a non-pathogenic variant (Landstrom et al., 2008).

The incorporation of ssTnI into cardiac muscle attenuated the dysfunction of myofilaments containing the HCM-associated cTnC mutants A8V and D145E. This suggests that ssTnI plays a protective role in regard to its ability to mitigate effects of disease-causing cTnC mutants in the heart. However, the protective role of ssTnI in cardiac muscle contraction is not a novel topic. We have previously shown that ssTnI has the ability to attenuate the functional consequences of two mutations in cTnT that are associated with restrictive cardiomyopathy (Pinto et al., 2008a, 2011b). Others have shown that the expression of ssTnI in the murine heart has a protective effect on skinned cardiac preparations and left ventricular function during stress conditions, such as acidosis (Wolska et al., 2001; Urboniene et al., 2005). As mentioned above, the presence of ssTnI in cardiac muscle preparation was not able to completely abolish the effect of the cTnC mutants A8V and D145E, as seen in Figure 4 in cardiac preparations reconstituted with ssTnI. This suggests that the presence of ssTnT in slow skeletal muscle may also play a role in rescuing the cTnC mutants' functional phenotype. Major differences exist between the structure of ssTnT and cTnT isoforms, where a large portion of the $\mathrm{N}$-terminus present in
cTnT is absent in ssTnT (Pinto et al., 2012). This region of cTnT has been shown to have important roles in regulating $\mathrm{Ca}^{2+}$ sensitization and activation of the skinned fibers due to effects on the dynamics of strong TnT-Tm interactions (Gomes et al., 2002; Gollapudi et al., 2012). Therefore, we speculate that some of the protective effect observed in slow skeletal muscle could be arising from the N-terminus of ssTnT.

While the crossover of mutation effects in both tissue types may lead to pathological consequences in both slow skeletal and cardiac muscle, manifestations may present themselves over distinctive time courses and with varying severities. When comparing the age of diagnosis and the symptoms of HCM patients in the cohort study that identified four variants in the TNNC1 gene, it is interesting to note that the patient bearing the $\mathrm{C} 84 \mathrm{Y}$ mutant was diagnosed at the earliest age (8.4 years) and exhibited syncope on exertion (Landstrom et al., 2008). Although syncope is a common event, it can signal more ominous underlying conditions (including HCM and arrhythmogenic right ventricular dysplasia) and outcomes such as sudden death (O'Connor et al., 1999). Alterations in skeletal muscle function may lead to additional downstream consequences that remain unknown. Function may be altered further by globally affecting signaling pathways that influence sarcomeric protein isoform switching and energy consumption. These changes could have profound consequences if the aberrant function arises in multiple muscle types, e.g., the cTnC mutants in slow skeletal muscle-despite slow muscle's fatigue-resistant properties that are associated with differential sensitivity to metabolite levels (Chase and Kushmerick, 1988, 1995) in normal individuals-could also be synergistic with regard to patient fatigue or muscle weakness. The true impact of skeletal and cardiac muscle dysfunction as a result of HCM mutations in the TNNC1 gene will bear out after examination of more cases within the clinic. Individuals affected by mutations in genes expressed more systemically have the potential to influence the time course and severity of disease; therefore, it is of interest to study the broader effects of mutations that may modify disease outcomes when manifesting in multiple muscle types.

\section{AUTHOR NOTE}

Part of this work was presented in the Biophysical Society $56^{\text {th }}$ Annual Meeting in San Diego, California, USA (February, 2012).

\section{AUTHOR CONTRIBUTIONS}

Performed experiments: TV, ML, DG, KJ, CM, and DD. Designed Study: TV, MP, DD, AL, PC, and JP. Analyzed Data: TV, ML, CM, DD, and JP. Wrote/Edited Manuscript: TV, ML, MP, DD, AL, PC, and JP.

\section{ACKNOWLEDGMENTS}

The authors would like to thank Jingsheng Liang for his technical assistance during this project. In addition, the 
authors thank the funding agencies that helped fund this work: National Institute of Health grants HL103840 and HL128683 (JP); American Heart Association postdoctoral fellowship \#09POST2300030 (MP); James and Esther King Foundation 1KD03-33923 (DD); National Center of Science and Technology for Structural Biology and Bioimaging, CENABIO, Brazil and Brazilian National Research Council, CNPq Science without Borders 229922/2013-9 (ML); fellowship from CNPq (TV). NIH-L40 (HL129273-01), the Pediatric and Congenital

\section{REFERENCES}

Albury, A. N., Swindle, N., Swartz, D. R., and Tikunova, S. B. (2012). Effect of hypertrophic cardiomyopathy-linked troponin $\mathrm{C}$ mutations on the response of reconstituted thin filaments to calcium upon troponin I phosphorylation. Biochemistry 51, 3614-3621. doi: 10.1021/bi300187k

Badr, M. A., Pinto, J. R., Davidson, M. W., and Chase, P. B. (2016). Fluorescent protein-based $\mathrm{Ca} 2+$ sensor reveals global, divalent cationdependent conformational changes in cardiac troponin C. PLoS ONE 11:e0164222. doi: 10.1371/journal.pone.0164222

Bradford, M. M. (1976). A rapid and sensitive method for the quantitation of microgram quantities of protein utilizing the principle of protein-dye binding. Anal. Biochem. 72, 248-254. doi: 10.1016/0003-2697(76)90527-3

Brouwer, W. P., van Dijk, S. J., Stienen, G. J., van Rossum, A. C., van der Velden, J., and Germans, T. (2011). The development of familial hypertrophic cardiomyopathy: from mutation to bedside. Eur. J. Clin. Invest. 41, 568-578. doi: 10.1111/j.1365-2362.2010.02439.x

Caforio, A. L., Rossi, B., Risaliti, R., Siciliano, G., Marchetti, A., Angelini, C., et al. (1989). Type 1 fiber abnormalities in skeletal muscle of patients with hypertrophic and dilated cardiomyopathy: evidence of subclinical myogenic myopathy. J. Am. Coll. Cardiol. 14, 1464-1473. doi: 10.1016/0735-1097(89)90383-5

Chalovich, J. M. (2012). Disease causing mutations of troponin alter regulated actin state distributions. J. Muscle Res. Cell Motil. 33, 493-499. doi: 10.1007/s10974-012-9305-x

Chase, P. B., and Kushmerick, M. J. (1988). Effects of pH on contraction of rabbit fast and slow skeletal muscle fibers. Biophys. J. 53, 935-946. doi: 10.1016/S0006-3495(88)83174-6

Chase, P. B., and Kushmerick, M. J. (1995). Effect of physiological ADP concentrations on contraction of single skinned fibers from rabbit fast and slow muscles. Am. J. Physiol. 268, C480-C489.

Chung, W. K., Kitner, C., and Maron, B. J. (2011). Novel frameshift mutation in Troponin C (TNNC1) associated with hypertrophic cardiomyopathy and sudden death. Cardiol. Young 21, 345-348. doi: 10.1017/S1047951110001927

Darin, N., Tajsharghi, H., Ostman-Smith, I., Gilljam, T., and Oldfors, A. (2007). New skeletal myopathy and cardiomyopathy associated with a missense mutation in MYH7. Neurology 68, 2041-2042. doi: 10.1212/01.wnl.0000264430.55233.72

Dweck, D., Reyes-Alfonso, A., and Potter, J. D. (2005). Expanding the range of free calcium regulation in biological solutions. Anal. Biochem. 347, 303-315. doi: 10.1016/j.ab.2005.09.025

Farah, C. S., and Reinach, F. C. (1995). The troponin complex and regulation of muscle contraction. FASEB J. 9, 755-767.

Fiske, C. H., and Subbarow, Y. (1925). The colorimetric determination of phosphorous. J. Biol. Chem. 66, 375-400.

Force, T., Bonow, R. O., Houser, S. R., Solaro, R. J., Hershberger, R. E., Adhikari, B., et al. (2010). Research priorities in hypertrophic cardiomyopathy: report of a Working Group of the National Heart, Lung, and Blood Institute. Circulation 122, 1130-1133. doi: 10.1161/CIRCULATIONAHA.110. 950089

Geisterfer-Lowrance, A. A., Kass, S., Tanigawa, G., Vosberg, H. P., McKenna, W., Seidman, C. E., et al. (1990). A molecular basis for familial hypertrophic cardiomyopathy: a beta cardiac myosin heavy chain gene missense mutation. Cell 62, 999-1006. doi: 10.1016/0092-8674(90)90274-I
Electrophysiology Society Paul C. Gillette Award, and pilot grant funding from the Baylor College of Medicine Department of Pediatrics (AL).

\section{SUPPLEMENTARY MATERIAL}

The Supplementary Material for this article can be found online at: http://journal.frontiersin.org/article/10.3389/fphys. 2017.00221/full\#supplementary-material

Gillis, T. E., Martyn, D. A., Rivera, A. J., and Regnier, M. (2007). Investigation of thin filament near-neighbour regulatory unit interactions during force development in skinned cardiac and skeletal muscle. J. Physiol. 580, 561-576. doi: 10.1113 /jphysiol.2007.128975

Goldfarb, L. G., and Dalakas, M. C. (2009). Tragedy in a heartbeat: malfunctioning desmin causes skeletal and cardiac muscle disease. J. Clin. Invest. 119, 1806-1813. doi: 10.1172/JCI38027

Gollapudi, S. K., Mamidi, R., Mallampalli, S. L., and Chandra, M. (2012). The Nterminal extension of cardiac troponin $\mathrm{T}$ stabilizes the blocked state of cardiac thin filament. Biophys. J. 103, 940-948. doi: 10.1016/j.bpj.2012.07.035

Gomes, A. V., Guzman, G., Zhao, J., and Potter, J. D. (2002). Cardiac troponin $\mathrm{T}$ isoforms affect the $\mathrm{Ca} 2+$ sensitivity and inhibition of force development: insights into the role of troponin T isoforms in the heart. J. Biol. Chem. 277, 35341-35349. doi: 10.1074/jbc.m204118200

Harvey, P. A., and Leinwand, L. A. (2011). The cell biology of disease: cellular mechanisms of cardiomyopathy. J. Cell Biol. 194, 355-365. doi: $10.1083 /$ jcb. 201101100

Hedera, P., Petty, E. M., Bui, M. R., Blaivas, M., and Fink, J. K. (2003). The second kindred with autosomal dominant distal myopathy linked to chromosome 14q: genetic and clinical analysis. Arch. Neurol. 60, 1321-1325. doi: 10.1001/archneur.60.9.1321

Hill, A. V. (1910). The possible effects of the aggregation of the molecules of haemoglobin on its dissociation curves. J. Physiol. 40 (Suppl.), iv-vii.

Hoffmann, B., Schmidt-Traub, H., Perrot, A., Osterziel, K. J., and Gessner, R. (2001). First mutation in cardiac troponin C, L29Q, in a patient with hypertrophic cardiomyopathy. Hum. Mutat. 17, 524. doi: 10.1002/humu.1143

Homayoun, H., Khavandgar, S., Hoover, J. M., Mohsen, A. W., Vockley, J., Lacomis, D., et al. (2011). Novel mutation in MYH7 gene associated with distal myopathy and cardiomyopathy. Neuromuscul. Disord. 21, 219-222. doi: 10.1016/j.nmd.2010.12.005

Hootsmans, W. J., and Meerschwam, I. S. (1971). Electromyography in patients with hypertrophic obstructive cardiomyopathy. Neurology 21, 810-816. doi: 10.1212/WNL.21.8.810

Hwang, P. M., Cai, F., Pineda-Sanabria, S. E., Corson, D. C., and Sykes, B. D. (2014). The cardiac-specific N-terminal region of troponin I positions the regulatory domain of troponin C. Proc. Natl. Acad. Sci. U.S.A. 111, 14412-14417. doi: 10.1073/pnas.1410775111

Jaafar, N., Girolami, F., Zairi, I., Kraiem, S., Hammami, M., and Olivotto, I. (2015). Genetic profile of hypertrophic cardiomyopathy in Tunisia: Is it different? Glob. Cardiol. Sci. Pract. 2015:16. doi: 10.5339/gcsp.2015.16

Jayasundar, J. J., Xing, J., Robinson, J. M., Cheung, H. C., and Dong, W. J. (2014). Molecular dynamics simulations of the cardiac troponin complex performed with FRET distances as restraints. PLoS ONE 9:e87135. doi: 10.1371/journal.pone.0087135

Karandreas, N., Stathis, P., Anastasakis, A., Rigopoulos, A., Piperos, P., Theopistou, A., et al. (2000). Electromyographic evidence of subclinical myopathy in hypertrophic cardiomyopathy. Muscle Nerve 23, 1856-1861. doi: 10.1002/1097-4598(200012)23:12<1856::AID-MUS9>3.0.CO;2-T

Laemmli, U. K. (1970). Cleavage of structural proteins during the assembly of the head of bacteriophage T4. Nature 227, 680-685. doi: 10.1038/227680a0

Lamont, P. J., Udd, B., Mastaglia, F. L., de Visser, M., Hedera, P., Voit, T., et al. (2006). Laing early onset distal myopathy: slow myosin defect with variable abnormalities on muscle biopsy. J. Neurol. Neurosurg. Psychiatr. 77, 208-215. doi: 10.1136/jnnp.2005.073825 
Lamont, P. J., Wallefeld, W., Hilton-Jones, D., Udd, B., Argov, Z., Barboi, A. C., et al. (2014). Novel mutations widen the phenotypic spectrum of slow skeletal/ $\beta$-cardiac myosin (MYH7) distal myopathy. Hum. Mutat. 35, 868-879. doi: 10.1002/humu.22553

Landstrom, A. P., and Ackerman, M. J. (2012). Beyond the cardiac myofilament: hypertrophic cardiomyopathy- associated mutations in genes that encode calcium-handling proteins. Curr. Mol. Med. 12, 507-518. doi: $10.2174 / 156652412800620020$

Landstrom, A. P., Parvatiyar, M. S., Pinto, J. R., Marquardt, M. L., Bos, J. M., Tester, D. J., et al. (2008). Molecular and functional characterization of novel hypertrophic cardiomyopathy susceptibility mutations in TNNC1-encoded troponin C. J. Mol. Cell. Cardiol. 45, 281-288. doi: 10.1016/j.yjmcc.2008.05.003

Li, M. X., and Hwang, P. M. (2015). Structure and function of cardiac troponin C (TNNC1): Implications for heart failure, cardiomyopathies, and troponin modulating drugs. Gene 571, 153-166. doi: 10.1016/j.gene.2015.07.074

Li, Z. L., Lilienbaum, A., Butler-Browne, G., and Paulin, D. (1989). Human desmin-coding gene: complete nucleotide sequence, characterization and regulation of expression during myogenesis and development. Gene 78, 243-254. doi: 10.1016/0378-1119(89)90227-8

Lochner, A., Hewlett, R. H., O’Kennedy, A., van der Walt, J. J., Tiedt, F. A., Hoffman, H., et al. (1981). A study of a family with inherited disease of cardiac and skeletal muscle. Part II. Skeletal muscle morphology and mitochondrial oxidative phosphorylation. S. Afr. Med. J. 59, 453-461.

Macera, M. J., Szabo, P., Wadgaonkar, R., Siddiqui, M. A., and Verma, R. S. (1992). Localization of the gene coding for ventricular myosin regulatory light chain (MYL2) to human chromosome 12q23-q24.3. Genomics 13, 829-831. doi: 10.1016/0888-7543(92)90161-K

Margossian, S. S., and Lowey, S. (1982). Preparation of myosin and its subfragments from rabbit skeletal muscle. Methods Enzymol. 85(Pt B), 55-71. doi: 10.1016/0076-6879(82)85009-X

Marian, A. J. (2010). Hypertrophic cardiomyopathy: from genetics to treatment. Eur. J. Clin. Invest. 40, 360-369. doi: 10.1111/j.1365-2362.2010.02268.x

Maron, B. J., and Maron, M. S. (2013). Hypertrophic cardiomyopathy. Lancet 381, 242-255. doi: 10.1016/S0140-6736(12)60397-3

Maron, B. J., Maron, M. S., and Semsarian, C. (2012). Genetics of hypertrophic cardiomyopathy after 20 years: clinical perspectives. J. Am. Coll. Cardiol. 60, 705-715. doi: 10.1016/j.jacc.2012.02.068

Marques, M. A., Pinto, J. R., Moraes, A. H., Iqbal, A., de Magalhaes, M. T., Monteiro, J., et al. (2017). Allosteric transmission along a loosely structured backbone allows a cardiac troponin $\mathrm{C}$ mutant to function with only one $\mathrm{Ca} 2+$ ion. J. Biol. Chem. 292, 2379-2394. doi: 10.1074/jbc.M116.765362

Martins, A. S., Parvatiyar, M. S., Feng, H. Z., Bos, J. M., GonzalezMartinez, D., Vukmirovic, M., et al. (2015). In vivo analysis of troponin C knock-In (A8V) mice: evidence that TNNC1 is a hypertrophic cardiomyopathy susceptibility gene. Circ. Cardiovasc Genet. 8, 653-664. doi: 10.1161/CIRCGENETICS.114.000957

Mastaglia, F. L., Lamont, P. J., and Laing, N. G. (2005). Distal myopathies. Curr. Opin. Neurol. 18, 504-510. doi: 10.1097/01.wco.0000175936.23945.b6

Matsuoka, R., Yoshida, M. C., Kanda, N., Kimura, M., Ozasa, H., Takao, A., et al. (1989). Human cardiac myosin heavy chain gene mapped within chromosome region 14q11.2 $\longrightarrow \mathrm{q} 13$. Am. J. Med. Genet. 32, 279-284. doi: 10.1002/ajmg.1320320234

Meredith, C., Herrmann, R., Parry, C., Liyanage, K., Dye, D. E., Durling, H. J., et al. (2004). Mutations in the slow skeletal muscle fiber myosin heavy chain gene (MYH7) cause laing early-onset distal myopathy (MPD1). Am. J. Hum. Genet. 75, 703-708. doi: 10.1086/424760

Meyer, N. L., and Chase, P. B. (2016). Role of cardiac troponin I carboxy terminal mobile domain and linker sequence in regulating cardiac contraction. Arch. Biochem. Biophys. 601, 80-87. doi: 10.1016/j.abb.2016.03.010

O'Connor, F. G., Oriscello, R. G., and Levine, B. D. (1999). Exercise-related syncope in the young athlete: reassurance, restriction or referral? Am. Fam. Phys. 60, 2001-2008.

Overeem, S., Schelhaas, H. J., Blijham, P. J., Grootscholten, M. I., ter Laak, H. J., Timmermans, J., et al. (2007). Symptomatic distal myopathy with cardiomyopathy due to a MY77 mutation. Neuromuscul. Disord. 17, 490-493. doi: 10.1016/j.nmd.2007.02.007

Parvatiyar, M. S., Landstrom, A. P., Figueiredo-Freitas, C., Potter, J. D., Ackerman, M. J., and Pinto, J. R. (2012). A mutation in TNNC1-encoded cardiac troponin
C, TNNC1-A31S, Predisposes to hypertrophic cardiomyopathy and ventricular fibrillation. J. Biol. Chem. 287, 31845-31855. doi: 10.1074/jbc.M112.377713

Pinto, J. R., Gomes, A. V., Jones, M. A., Liang, J., Nguyen, S., Miller, T., et al. (2012). The functional properties of human slow skeletal troponin $\mathrm{T}$ isoforms in cardiac muscle regulation. J. Biol. Chem. 287, 37362-37370. doi: 10.1074/jbc.M112.364927

Pinto, J. R., Parvatiyar, M. S., Jones, M. A., Liang, J., Ackerman, M. J., and Potter, J. D. (2009). A functional and structural study of troponin C mutations related to hypertrophic cardiomyopathy. J. Biol. Chem. 284, 19090-19100. doi: 10.1074/jbc.M109.007021

Pinto, J. R., Parvatiyar, M. S., Jones, M. A., Liang, J., and Potter, J. D. (2008a). A troponin $\mathrm{T}$ mutation that causes infantile restrictive cardiomyopathy increases $\mathrm{Ca} 2+$ sensitivity of force development and impairs the inhibitory properties of troponin. J. Biol. Chem. 283, 2156-2166. doi: 10.1074/jbc.M707066200

Pinto, J. R., Reynaldo, D. P., Parvatiyar, M. S., Dweck, D., Liang, J., Jones, M. A., et al. (2011a). Strong cross-bridges potentiate the $\mathrm{Ca}(2+)$ affinity changes produced by hypertrophic cardiomyopathy cardiac troponin C mutants in myofilaments: a fast kinetic approach. J. Biol. Chem. 286, 1005-1013. doi: 10.1074/jbc.M110.168583

Pinto, J. R., Veltri, T., and Sorenson, M. M. (2008b). Modulation of troponin C affinity for the thin filament by different cross-bridge states in skinned skeletal muscle fibers. Pflugers Arch. 456, 1177-1187. doi: 10.1007/s00424-008-0480-y

Pinto, J. R., Yang, S. W., Hitz, M. P., Parvatiyar, M. S., Jones, M. A., Liang, J., et al (2011b). Fetal cardiac troponin isoforms rescue the increased $\mathrm{Ca} 2+$ sensitivity produced by a novel double deletion in cardiac troponin $\mathrm{T}$ linked to restrictive cardiomyopathy: a clinical, genetic, and functional approach. J. Biol. Chem. 286, 20901-20912. doi: 10.1074/jbc.M111.234336

Ploski, R., Rydzanicz, M., Ksiazczyk, T. M., Franaszczyk, M., Pollak, A., Kosinska, J., et al. (2016). Evidence for troponin C (TNNC1) as a gene for autosomal recessive restrictive cardiomyopathy with fatal outcome in infancy. Am. J. Med. Genet. A. 170, 3241-3248. doi: 10.1002/ajmg.a.37860

Przybojewski, J. Z., Hoffman, H., de Graaf, A. S., van der Walt, J. J., Tiedt, F. A., O'Kennedy, A., et al. (1981). A study of a family with inherited disease of cardiac and skeletal muscle. Part I. Clinical, electrocardiographic, echocardiographic, haemodynamic, electrophysiological and electron microscopic studies. S. Afr. Med. J. 59, 363-373.

Schoffstall, B., LaBarbera, V. A., Brunet, N. M., Gavino, B. J., Herring, L., Heshmati, S., et al. (2011). Interaction between troponin and myosin enhances contractile activity of myosin in cardiac muscle. DNA Cell Biol. 30, 653-659. doi: 10.1089/dna.2010.1163

Seidman, C. E., and Seidman, J. G. (2011). Identifying sarcomere gene mutations in hypertrophic cardiomyopathy: a personal history. Circ. Res. 108, 743-750. doi: $10.1161 /$ circresaha.110.223834

Semsarian, C., Ingles, J., Maron, M. S., and Maron, B. J. (2015). New perspectives on the prevalence of hypertrophic cardiomyopathy. J. Am. Coll. Cardiol. 65, 1249-1254. doi: 10.1016/j.jacc.2015.01.019

Smith, E. R., Heffernan, L. P., Sangalang, V. E., Vaughan, L. M., and Flemington, C. S. (1976). Voluntary muscle involvement in hypertrophic cardiomyopathy. A study of eleven patients. Ann. Intern. Med. 85, 566-572. doi: 10.7326/0003-4819-85-5-566

Solaro, R. J., Pang, D. C., and Briggs, F. N. (1971). The purification of cardiac myofibrils with Triton X-100. Biochim. Biophys. Acta 245, 259-262. doi: 10.1016/0005-2728(71)90033-8

Song, W. J., Van Keuren, M. L., Drabkin, H. A., Cypser, J. R., Gemmill, R. M., and Kurnit, D. M. (1996). Assignment of the human slow twitch skeletal muscle/cardiac troponin C gene (TNNC1) to human chromosome 3p21.3->3p14.3 using somatic cell hybrids. Cytogenet. Cell Genet. 75, 36-37. doi: $10.1159 / 000134453$

Tajsharghi, H., Oldfors, A., Macleod, D. P., and Swash, M. (2007). Homozygous mutation in MYH7 in myosin storage myopathy and cardiomyopathy. Neurology 68, 962. doi: 10.1212/01.wnl.0000257131.13438.2c

Tajsharghi, H., Thornell, L. E., Lindberg, C., Lindvall, B., Henriksson, K. G., and Oldfors, A. (2003). Myosin storage myopathy associated with a heterozygous missense mutation in MYH7. Ann. Neurol. 54, 494-500. doi: 10.1002/ana. 10693

Takeda, S., Yamashita, A., Maeda, K., and Maeda, Y. (2003). Structure of the core domain of human cardiac troponin in the $\mathrm{Ca}(2+)$-saturated form. Nature 424 , 35-41. doi: 10.1038/nature01780 
Talmadge, R. J., and Roy, R. R. (1993). Electrophoretic separation of rat skeletal muscle myosin heavy-chain isoforms. J. Appl. Physiol. 75, 2337-2340.

Teare, D. (1958). Asymmetrical hypertrophy of the heart in young adults. Br. Heart J. 20, 1-8. doi: 10.1136/hrt.20.1.1

Towbin, J. A. (2014). Inherited cardiomyopathies. Circ. J. 78, 2347-2356. doi: 10.1253/circj.CJ-14-0893

Tripet, B., Van Eyk, J. E., and Hodges, R. S. (1997). Mapping of a second actintropomyosin and a second troponin $\mathrm{C}$ binding site within the $\mathrm{C}$ terminus of troponin $\mathrm{I}$, and their importance in the $\mathrm{Ca} 2+$-dependent regulation of muscle contraction. J. Mol. Biol. 271, 728-750. doi: 10.1006/jmbi.19 97.1200

Urboniene, D., Dias, F. A., Pena, J. R., Walker, L. A., Solaro, R. J., and Wolska, B. M. (2005). Expression of slow skeletal troponin I in adult mouse heart helps to maintain the left ventricular systolic function during respiratory hypercapnia. Circ. Res. 97, 70-77. doi: 10.1161/01.RES.0000173849.68636.1e

Vinogradova, M. V., Stone, D. B., Malanina, G. G., Karatzaferi, C., Cooke, R., Mendelson, R. A., et al. (2005). $\mathrm{Ca}^{2+}$-regulated structural changes in troponin. Proc. Natl. Acad. Sci. U.S.A. 102, 5038-5043. doi: 10.1073/pnas.04088 82102

Westfall, M. V., Rust, E. M., and Metzger, J. M. (1997). Slow skeletal troponin I gene transfer, expression, and myofilament incorporation enhances adult cardiac myocyte contractile function. Proc. Natl. Acad. Sci. U.S.A. 94, 5444-5449. doi: 10.1073/pnas.94.10.5444

Weterman, M. A., Barth, P. G., van Spaendonck-Zwarts, K. Y., Aronica, E., PollThe, B. T., Brouwer, O. F., et al. (2013). Recessive MYL2 mutations cause infantile type I muscle fibre disease and cardiomyopathy. Brain 136, 282-293. doi: 10.1093/brain/aws293

Willott, R. H., Gomes, A. V., Chang, A. N., Parvatiyar, M. S., Pinto, J. R., and Potter, J. D. (2010). Mutations in Troponin that cause HCM, DCM AND RCM: what can we learn about thin filament function? J. Mol. Cell. Cardiol. 48, 882-892. doi: 10.1016/j.yjmcc.2009.10.031

Wolska, B. M., Vijayan, K., Arteaga, G. M., Konhilas, J. P., Phillips, R. M., Kim, R., et al. (2001). Expression of slow skeletal troponin I in adult transgenic mouse heart muscle reduces the force decline observed during acidic conditions. $J$. Physiol. 536, 863-870. doi: 10.1111/j.1469-7793.2001.00863.x

Zhang, R., Zhao, J., and Potter, J. D. (1995). Phosphorylation of both serine residues in cardiac troponin $\mathrm{I}$ is required to decrease the $\mathrm{Ca} 2+$ affinity of cardiac troponin C. J. Biol. Chem. 270, 30773-30780. doi: 10.1074/jbc.270.51.30773

Zot, H. G., Hasbun, J. E., Michell, C. A., Landim-Vieira, M., and Pinto, J. R. (2016). Enhanced troponin I binding explains the functional changes produced by the hypertrophic cardiomyopathy mutation A8V of cardiac troponin C. Arch. Biochem. Biophys. 601, 97-104. doi: 10.1016/j.abb.2016.03.011

Conflict of Interest Statement: The authors declare that the research was conducted in the absence of any commercial or financial relationships that could be construed as a potential conflict of interest.

The reviewer DWDK and handling Editor declared their shared affiliation, and the handling Editor states that the process nevertheless met the standards of a fair and objective review.

Copyright (C) 2017 Veltri, Landim-Vieira, Parvatiyar, Gonzalez-Martinez, Dieseldorff Jones, Michell, Dweck, Landstrom, Chase and Pinto. This is an open-access article distributed under the terms of the Creative Commons Attribution License (CC BY). The use, distribution or reproduction in other forums is permitted, provided the original author(s) or licensor are credited and that the original publication in this journal is cited, in accordance with accepted academic practice. No use, distribution or reproduction is permitted which does not comply with these terms. 